\title{
openheart Worksite intervention study to prevent diabetes in Nepal: a randomised trial protocol
}

Prajjwal Pyakurel (D) , ${ }^{1}$ Archana Shrestha, ${ }^{2}$ Biraj M Karmacharya, ${ }^{2}$ Shyam S Budhathoki, ${ }^{3}$ Rajendra Kumar Chaudhari, ${ }^{1}$ Dipesh Tamrakar, ${ }^{2}$ Abha Shrestha, ${ }^{2}$ Robin M Karmacharya, ${ }^{2}$ Anmol Shrestha, ${ }^{2}$ Sumitra Sharma, ${ }^{4}$ Sanjib Kumar Sharma, ${ }^{1}$ Donna Spiegelman ${ }^{5}$

To cite: Pyakurel P, Shrestha A, Karmacharya BM, et al. Worksite intervention study to prevent diabetes in Nepal: a randomised trial protocol. Open Heart 2020;7:e001236. doi:10.1136/ openhrt-2019-001236

Received 1 January 2020 Revised 3 July 2020 Accepted 6 July 2020

\section{Check for updates}

C) Author(s) (or their employer(s)) 2020. Re-use permitted under CC BY-NC. No commercial re-use. See rights and permissions. Published by BMJ.

${ }^{1}$ B.P. Koirala Institute of Health Sciences, Dharan, Nepal ${ }^{2}$ Kathmandu University School of Medical Sciences, Kathmandu, Nepal

${ }^{3}$ Golden Community Hospital, Lalitpur, Nepal

${ }^{4}$ Kathmadnu Medical College Teaching Hospital, Kathmandu, Nepal

${ }^{5}$ Yale School of Public Health, New Haven, Connecticut, USA

Correspondence to Dr Prajjwal Pyakurel; prazzwal@ gmail.com

\section{ABSTRACT}

Introduction In Nepal, approximately $31 \%$ of adult industrial employees have diabetes. While the prevention of type 2 diabetes through behavioural intervention has been disseminated, worksite could be an effective platform for the translation of this knowledge into action as employed adults spend most of their workday waking hours at workplaces.

Methods and analysis We will conduct a randomised controlled trial to assess the effectiveness of a behavioural and a canteen intervention on diabetes risk reduction among those who are prediabetic at two worksites in eastern Nepal. We will recruit 162 adult full-time factory workers with haemoglobin $\mathrm{A} 1 \mathrm{c}(\mathrm{HbA} 1 \mathrm{c})$ of $5.7 \%-6.4 \%$ at baseline or fasting blood sugar of $100-125 \mathrm{mg} / \mathrm{dL}$. The 8-14 months' control period will be followed by the behavioural intervention where half of the participants will be randomised to receive the behavioural intervention and half will act as a control and will not receive any intervention. Then, all participants will receive the canteen intervention. The analysis will be intent-to-treat, comparing the difference in the change in $\mathrm{HbA} 1 \mathrm{c} \%$ between the behavioural intervention group and the control group using a two-sample t-test. The withinparticipant changes in $\mathrm{HbA} 1 \mathrm{c}$ after 6 or more months on the canteen intervention among those not randomised to the behavioural intervention in the previous period will be assessed using the paired t-test.

Ethics and dissemination Ethical approval was obtained from the Institutional Review Board at Yale School of Public Health, New Havens, USA and the Nepal Health Research Council.

Trial registration number NCT04161937.

\section{INTRODUCTION}

Diabetes is the fifth leading cause of death in most high-income countries and there is substantial evidence that it is epidemic in many low-income and middle-income countries. $^{1}$ The global (age standardised) prevalence of diabetes has nearly doubled since 1980 , rising from $4.7 \%$ to $8.5 \%$ in adults. ${ }^{2}$ Complications from diabetes, such as cardiovascular diseases (CVDs) and peripheral vascular disease, stroke, diabetic neuropathy, peripheral arterial diseases, amputations, renal failure and blindness, results in disability, reduced life expectancy and enormous healthcare costs. ${ }^{3}$ In Nepal, there is a lack of reliable and representative data on the prevalence of type 2 diabetes. Various small studies from different parts of the country in different population groups have found prevalence rates ranging from $6.3 \%$ to $8.5 \%{ }^{4}$ The recently conducted STEPwise approach to surveillance (STEPS) survey for noncommunicable disease risk factors found the prevalence of diabetes to be $5.8 \% .^{5}$ A pilot study among adult employees in an industrial setting found a diabetes prevalence of $4 \%$ and $31 \%$ for prediabetes. ${ }^{6}$ The prevention of type 2 diabetes through behavioural interventions has been established by several clinical trials. ${ }^{7}$ These studies had a strong focus on increased physical activity, dietary modifications and weight reduction among overweight participants. The US Diabetes Prevention Program (DPP) trial demonstrated that structured behaviour interventions-such as training people with prediabetes to achieve modest weight loss through diet and physical activity-reduced 3-year diabetes incidence by $58 \% .^{8}$ Lifestyle interventions and beneficial changes in diet have been reported to be effective in improving blood glucose control. ${ }^{9}$ Additionally, lifestyle intervention has been found to reduce the development of comorbidities in patients with type 2 diabetes. ${ }^{10}$ Several studies have investigated the effect of diet-focused and other lifestylefocused interventions in workplace settings. A systematic review and meta-analysis of health promotion at workplaces over the past 20 years found a positive impact on physical activity, diet, smoking, weight loss and health promotion. ${ }^{11}$ However, the translation of this knowledge to real-world settings has been a 
challenge. Worksites could be an effective platform for translating this knowledge into action because employed adults spend most of their workday waking hours at workplaces. ${ }^{12}$ Workplaces have additional advantages because of the convenience reaching people; social support; existing formal and informal communication networks; and possible corporate behaviour network. ${ }^{12} 13$ Studies have shown a positive impact of diabetes prevention at the worksite and other settings. ${ }^{1415}$

In 2013, we conducted a survey of cardiovascular disease risk factors among employees of a wire factory in eastern Nepal. The study showed that about a third of the employees were prediabetic and $4 \%$ had diabetes. ${ }^{6}$ We established an ongoing worksite screening and preventive cardiovascular disease care programme in this wire industry and a textile factory in January 2016. Furthermore, we conducted a qualitative study to understand willingness, facilitators and barriers for the promotion of healthier eating in the industry cafeterias. ${ }^{16}$ Building on this groundwork, we propose a pre-post trial to (1) measure the effectiveness of an individual-levelbehavioural education on diabetes risk reduction by comparing the change in haemoglobin A1c (HbA1c)\% of participants 6 months after the beginning of the behavioural intervention with the change over 8-14 months of a preliminary control period and (2) to measure the effectiveness of an environmental-level cafeteria intervention on the risk of diabetes prevention by comparing participants' change in $\mathrm{HbA1c} \%$ after 6 months of canteen intervention with those not randomised to the behavioural intervention in the previous period.

\section{IMPACT OF THE RESEARCH}

The prevalence of diabetes is increasing in low-income and middle-income countries. Diabetes was the leading cause of loss in DisabilityAdjusted Life Years (DALYs) and had a higher percentage change from 2007 to 2017 in Nepal for communicable, maternal, neonatal and nutritional diseases, non-communicable diseases and injuries. Hence, it is of utmost importance to prevent diabetes and its complications. Worksites could be an effective platform for the translation of this knowledge into action as employed adults spend most of their workday waking hours at workplaces. To our knowledge, this is one of the biggest multicentre trials for diabetes prevention in Nepal. Hence, the results of our study could be used by policy-makers to develop appropriate, context-specific guidelines for diabetes prevention in the country.

\section{METHODS AND ANALYSIS \\ Study design}

We will conduct a two-phase trial. In the first phase, we will undertake a randomised controlled trial to measure the effectiveness of an individual-level behavioural intervention to reduce diabetes risk factors. The change in HbA1c, a marker of diabetes, will be compared for those randomised to behavioural intervention with those not randomised to behavioural intervention over the same time period. In the second step, we will conduct a prepost intervention to measure the effectiveness of an environmental-level cafeteria intervention. The changes in HbAlc over canteen intervention will be compared with those not randomised to the behavioural intervention in the previous period (figure 1).

\section{Study setting}

The interventions will be conducted at two worksites: (a) Hulas Wire Industry and (b) Pragati Textile Industry, both located in the Sunsari-Morang industrial corridor of eastern Nepal. We selected these two sites because of their interest in research, the dedication of the management team to the canteen, the willingness of the management to commit workers' time in research without impairing pay cut and for the provision of office space for the research team. They are also excellent settings because of (a) the high prevalence of prediabetes, ${ }^{6}$ (b) there has not been any intervention at the national or local level to address the burden of prediabetes and diabetes in such settings; and (c) opportunity to engage low socioeconomic status participants who work in these settings.

\section{Inclusion criteria}

Full-time employees of the Hulas Wire and Pragati Textile companies aged 18 years or above with HbAlc of $5.7 \%-$ $6.4 \%$ at baseline and/or fasting blood sugar (FBS) of $100-125 \mathrm{mg} / \mathrm{dL}$ will be enrolled in the study.

\section{Exclusion criteria}

Pregnant women, hypertensive and diabetic patients on medication will be excluded from the study.

\section{Sample size and power}

The study sample includes all the permanent industrial workers in the Hulas Wire and Pragati Textile industry of eastern Nepal. There are 765 permanent workers at these worksites. We expect 500 of them will participate in the screening (table 1). Based on our previous survey in the same industry, ${ }^{6}$ we expect $153(30.5 \%)$ to be prediabetic (HbAlc between $5.7 \%$ and $6.4 \%$ ) and be invited in the study. The SD of the difference in $\mathrm{HbA1c} \%$ after a 6-month intervention in another worksite setting was $1.75 \%$ with a mean of $-0.87 \% .^{15}$ Assuming no change in the comparison group, a similar SD and sample size of 153 participants, using a two-sample t-test for the difference between two within-group changes, the minimum detectable differences at $80 \%$ power and $5 \%$ level of significance are expected to be $-0.91 \%$ for behaviour intervention and $-0.72 \%$ for cafeteria intervention.

\section{Screening}

We will screen all consenting employees at these workplaces.

\section{Baseline assessment}

At baseline, research assistants (RAs) will administer a standardised questionnaire to record the age, sex, 


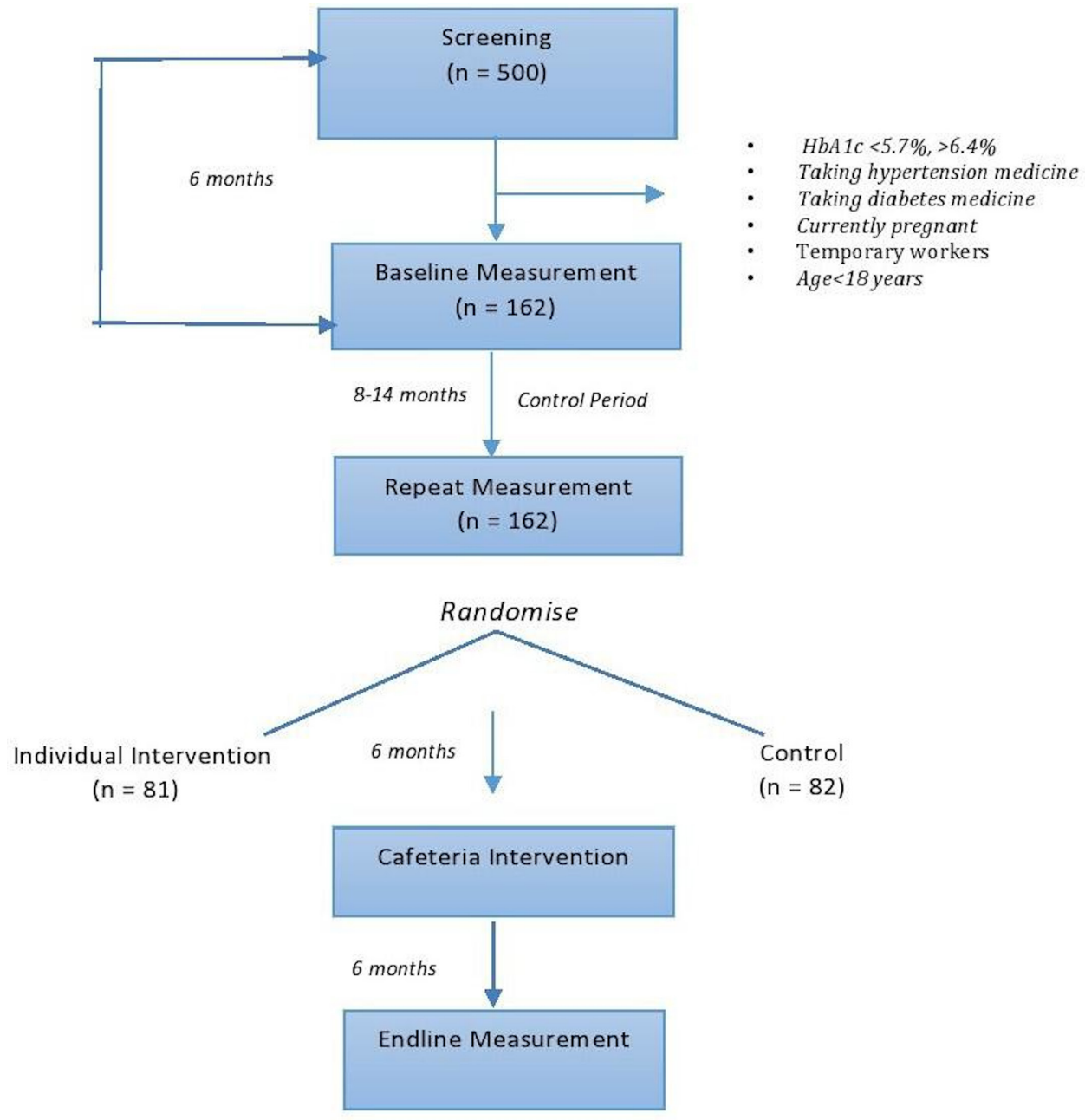

Figure 1 Study design, worksite intervention study. HbA1c, haemoglobin A1c.

education, income, marital status, family history of CVD, smoking, drinking and physical activity of the participants using Open Data Kit software. ${ }^{17}$ We will use the Global Physical Activity Questionnaire, ${ }^{18}$ to measure physical activity. The metabolic equivalent of task (MET) minutes per week will be calculated from the Global Physical Activity Questionnaire.

\section{4-hour dietary recall}

We will assess the dietary intake of the participants with 24-hour dietary recalls. We will conduct two structured interviews to record detailed information about foods and beverages consumed by the participants in the past 24 hours. Each questionnaire will take approximately half

Table 1 Data collection schedule for the worksite intervention study to prevent diabetes in Nepal

\begin{tabular}{|c|c|c|c|c|c|}
\hline & $\begin{array}{l}\text { Screening } \\
\text { month } 1\end{array}$ & $\begin{array}{l}\text { Baseline } \\
\text { month 1-2 }\end{array}$ & $\begin{array}{l}\text { First follow-up } \\
6 \text { months }\end{array}$ & $\begin{array}{l}\text { Second follow-up } \\
12 \text { months }\end{array}$ & $\begin{array}{l}\text { Third follow-up } \\
18 \text { months }\end{array}$ \\
\hline $\begin{array}{l}\text { Screening (age, sex, family history of diabetes, } \\
\text { occupational characteristics, physical measurements } \\
\text { (height, weight, waist circumference) }\end{array}$ & $x$ & & & & \\
\hline Demographics (age, sex, education, marital status) & & $\mathrm{x}$ & & & \\
\hline Lifestyle (smoking, drinking, physical activity) & & $\mathrm{x}$ & $\mathrm{x}$ & $x$ & $\mathrm{x}$ \\
\hline Diet (24-hour dietary recall) & & $\mathrm{X}$ & $\mathrm{X}$ & $x$ & $\mathrm{X}$ \\
\hline $\begin{array}{l}\text { Physical measurement (height, weight, waist } \\
\text { circumference) }\end{array}$ & & $x$ & $x$ & $x$ & $x$ \\
\hline Blood pressure & & $x$ & $x$ & $x$ & $x$ \\
\hline $\begin{array}{l}\text { Biochemical measurement (HbA1c, fasting glucose, } \\
\text { HDL, LDL, total cholesterol, triglycerides) }\end{array}$ & & $\mathrm{X}$ & $\mathrm{X}$ & $x$ & $\mathrm{X}$ \\
\hline
\end{tabular}

HDL, high-density lipoprotein; LDL, low-density lipoprotein. 
Table 2 Canteen intervention in the industrial sector of eastern Nepal

\begin{tabular}{|c|c|}
\hline Components & Activities \\
\hline $\begin{array}{l}\text { Strengthen canteen } \\
\text { management }\end{array}$ & $\begin{array}{l}\text { Formation of canteen intervention team (CIT) including industry managers, administrative department, union leaders, } \\
\text { canteen operators, security personnel investigator, research assistants, nutritionist } \\
\text { Training will be conducted for the CIT on a healthy diet; taking note of local context } \\
\text { Monthly meetings with CIT will be organised to monitor the intervention and discuss the challenges and barriers for effective } \\
\text { implementation and strategies for resolving them }\end{array}$ \\
\hline $\begin{array}{l}\text { Capacity building of cafeteria } \\
\text { employee }\end{array}$ & $\begin{array}{l}\text { Capacity assessment of the cafeteria employee will be undertaken to identify the strengths and weakness, form strategies } \\
\text { for addressing weakness and educate them on diabetes, hypertension and other cardiovascular disease prevention } \\
\text { strategies through healthy eating } \\
\text { Cooking classes will beconducted for canteen staff to promote healthy cooking practices in the canteen. We will gradually } \\
\text { promote healthy eating practices by developing and understanding workers food-related preferences, attitudes and } \\
\text { behaviours of people considering the local context } \\
\text { A team for weekly monitoring and evaluation of the cooking practices at the canteen will be formed }\end{array}$ \\
\hline $\begin{array}{l}\text { Food modification in the } \\
\text { canteen }\end{array}$ & $\begin{array}{l}\text { Healthy foods will replace unhealthy foods with context-specific culturally appropriate interventions } \\
\text { Some interventions to be developed are: } \\
\text { Replacing white rice with brown rice. Mixing brown rice with } 50 \% \text { white rice. We will consider adding older grains such as } \\
\text { millet, finger millet and sorghum in addition to or instead of the brown rice } \\
\text { Decreasing the amount of sugar in tea and adding cinnamon and/or ginger and lemon. We will promote lemon tea } \\
\text { Fresh fruits and vegetables will be introduced } \\
\text { The salt content in cooked vegetables and pulses will be lowered and we will encourage the use of onion, garlic and herbs to } \\
\text { add flavour } \\
\text { Less use of oil and the use of healthier locally available monosaturated and polyunsaturated oils will be encouraged } \\
\text { High sugary drinks will be replaced by water }\end{array}$ \\
\hline $\begin{array}{l}\text { Information Education and } \\
\text { Communication (IEC) }\end{array}$ & $\begin{array}{l}\text { A formal programme launch event will kick off the canteen intervention } \\
\text { The IEC package will consist of poster displays, pamphlets, healthy food presentation and group discussions } \\
\text { All the labour workers, administrative staffs, union leaders, section chief and executives will be invited to attend a brief half- } \\
\text { hour session on healthy eating and healthy food choices in the canteen }\end{array}$ \\
\hline
\end{tabular}

an hour to complete. We will record the participants' ID, date and day of interview along with activities conducted from wake up to the sleep time before inquiring about food consumption in the last 24 hours. We will record the time, place, food items, brand name/cooking methods, quantity and additional remarks during 24-hour dietary recall interviews. We will use a visual aid developed for the local context in the form of a show card to ascertain the exact consumption of food and beverages by the participants. $^{19}$

\section{Anthropometric measurements \\ Weight}

Weight will be measured using a portable crown digital scale and recorded nearest as $0.1 \mathrm{~kg}$. The scale will be placed on a flat surface and the participants will be asked to step on the scale barefoot with minimal clothing, without holding anything. The scale will be validated on a daily basis with known weights. ${ }^{20}$

\section{Standing height}

Height will be measured in centimetres. Standing height will be measured with the participants standing upright. Heels will be slightly separated touching the wall and the weight borne evenly on both feet. Heels, buttocks and scapulae will be brought in contact with a wall. The head will be positioned so that the participants will look straight ahead with a line of sight and chin parallel to the floor. The ruler will be kept firmly over the head to compress the hair. The height will then be recorded. ${ }^{21}$

\section{Waist circumference}

Waist circumference will be measured by placing the measuring tension tape midpoint between the lower margin of the last palpable rib and the top of the iliac crest. The participants will be asked to stand with their arms at the sides, feet positioned closed together and weight evenly distributed across the feet. ${ }^{22}$

\section{Hip circumference}

Hip circumference will be measured at the maximum circumference over the buttocks. The subject will be asked to stand with their arms at sides, feet positioned closely together and their weight evenly distributed across the feet. Hip circumference will be then measured at the end of a normal expiration. ${ }^{22}$

\section{Laboratory measurement}

Blood samples will be collected and analysed for HbAlc, fasting glucose, total cholesterol, triglycerides, highdensity lipoprotein (HDL) cholesterol and low-density lipoprotein (LDL) cholesterol at the clinical laboratory of a nearby tertiary care hospital, B.P. Koirala Institute of Health Sciences, Dharan, Nepal, where good clinical laboratory practices have been established. This laboratory is participating in an external quality assurance scheme of Christian Medical College, Vellore, India for the last 10 years. It is accredited by the National Accreditation Board for Testing and Calibration Laboratories, India. All of the laboratory procedures will be conducted 


\begin{tabular}{|c|c|c|}
\hline Characteristics & Frequency & Percent \\
\hline Age (years) (mean (SD) & $40.4(9.7)$ & \\
\hline \multicolumn{3}{|l|}{ Gender } \\
\hline Male & 162 & 100 \\
\hline \multicolumn{3}{|l|}{ Ethnicity } \\
\hline Terai Janjati & 87 & 54 \\
\hline Madhesi & 39 & 24 \\
\hline Brahmin/Chettri & 28 & 17 \\
\hline Others & 08 & \\
\hline \multicolumn{3}{|l|}{ Marital status } \\
\hline Married & 140 & 87 \\
\hline Not married & 20 & 12 \\
\hline Others & 02 & 1 \\
\hline \multicolumn{3}{|l|}{ Religion } \\
\hline Hindu & 162 & 100 \\
\hline \multicolumn{3}{|l|}{ Education } \\
\hline Less than high school & 140 & 86 \\
\hline High School or more & 22 & 14 \\
\hline Years of formal education, mean (SD) & $9.2(3.8)$ & \\
\hline
\end{tabular}

in the Biochemistry Department of B.P. Koirala Institute of Health Sciences, Dharan, Nepal. Blood samples for fasting glucose will be collected in $3 \mathrm{~mL}$ sodium fluoride and potassium oxalate vials. Blood samples for assessment of $\mathrm{HbA1c}$ and lipid profile will be collected in $3 \mathrm{~mL}$ EDTA and plain vials, respectively. The site principal investigator will ask the participants to fast for 8-10 hours 1 day before blood sample collection. The RAs will meet participants in person and will inform them of the date, time and location for blood sample collection. Those who miss the initial appointment will be reminded three times before withdrawing from the study.

To collect the blood specimens, the participants will be asked to sit comfortably in a chair and their arms hyperextended. A tourniquet will be placed just above the puncture site to expose the vein. An alcohol swap will be conducted in a circular manner beginning at the site and working outward. The needle will be inserted in a vein at a 15-30 degree angle with the surface of the arm. Blood samples will be collected using the appropriate blood collection tubes.

HbA1c will be measured using the turbidimetric inhibition immunoassay in haemolysed whole-blood fasting glucose by the hexokinase method, ${ }^{23}$ total cholesterol will be measured by cholesterol oxidase and peroxidase method, ${ }^{24}$ triglycerides by the glycerol-3 phosphate oxidase peroxidase method, ${ }^{25}$ LDL by the homogeneous enzymatic colorimetric method, ${ }^{26}$ and HDL by the homogeneous enzymatic colorimetric method. ${ }^{27}$ All the parameters will be measured in a Cobas c311, Roche/Hitachi autoanalyser.
Table 4 CVD risk factors of enrolled participants at baseline $(n=162)$

\begin{tabular}{lcl}
\hline Characteristics & Frequency & Percent \\
\hline Smoking & & \\
Never & 126 & 78 \\
Former & 16 & 10 \\
Current & 20 & 12 \\
Number of pack year for former and current smoker $(n=49)$ & \\
<5 pack year & 40 & 82 \\
$\geq 5$ pack year & 09 & 18 \\
\hline
\end{tabular}

Ever had alcohol

\begin{tabular}{|c|c|c|}
\hline No & 65 & 40 \\
\hline Yes & 97 & 60 \\
\hline \multicolumn{3}{|l|}{$\begin{array}{l}\text { Alcohol intake, drinks per day among } \\
\text { ever drinkers }(n=68)\end{array}$} \\
\hline 1 drink/day & 06 & 6 \\
\hline 2 drinks/day & 21 & 22 \\
\hline 3 drinks/day & 06 & 6 \\
\hline$>3$ drinks/day & 64 & 66 \\
\hline \multicolumn{3}{|l|}{ Total physical activity $(n=138)$} \\
\hline Low (<600 MET min/week) & 80 & 58 \\
\hline High ( $\geq 600 \mathrm{MET} \mathrm{min} /$ week) & 58 & 42 \\
\hline \multicolumn{3}{|l|}{ Body mass index $\left(\mathrm{kg} / \mathrm{m}^{2}\right)$} \\
\hline Underweight $<18.5$ & 06 & 4 \\
\hline Normal 18.5-24.9 & 85 & 52 \\
\hline Overweight 25-29.9 & 62 & 38 \\
\hline Obese $\geq 30$ & 09 & 6 \\
\hline Mean (SD) & $24.2(3.9)$ & \\
\hline \multicolumn{3}{|l|}{ Hypertension $(\mathrm{mm} \mathrm{Hg})$} \\
\hline Normal $<120 /<80$ & 51 & 31 \\
\hline Prehypertension 120-139/80-89 & 63 & 39 \\
\hline Hypertension $\geq 140 / \geq 90$ & 48 & 30 \\
\hline Systolic blood pressure, mean (SD) & $127.9(17.2)$ & \\
\hline Diastolic blood pressure, mean (SD) & $81.7(12.6)$ & \\
\hline
\end{tabular}

CVD, cardiovascular disease.

\section{Control period}

The waiting period will be of $8-14$ months before implementing any intervention. No contact will be made with the participants during the control period. The minimum time for the control period was 6 months to allow for sufficient time to detect a change in HbAlc. However, for practical reasons involved with rolling out the screening and recruitment at two study sites, we needed to extend the control period to 8-14 months.

\section{Randomisation}

Participants will be randomised into two groups. Half of the participants will receive behavioural intervention and half serve as a control and will not receive the behavioural intervention. Each participant will 


\begin{tabular}{|c|c|c|}
\hline Characteristics & Frequency & Percent \\
\hline \multicolumn{3}{|l|}{$\mathrm{HbA1c} \%$} \\
\hline Prediabetic (5.7-6.4) & 145 & 100 \\
\hline Mean (SD) & $5.9(0.1)$ & \\
\hline \multicolumn{3}{|l|}{ *Fasting blood sugar (mg/dL) } \\
\hline Prediabetic 100-125.9 & 17 & 100 \\
\hline Mean (SD) & $116.1(9.1)$ & \\
\hline \multicolumn{3}{|c|}{ Total cholesterol $(\mathrm{mg} / \mathrm{dL})(\mathrm{n}=145)$} \\
\hline Normal $<200$ & 87 & 63 \\
\hline Borderline 200-239 & 30 & 22 \\
\hline High $\geq 240$ & 20 & 15 \\
\hline Missing & 08 & \\
\hline Mean (SD) & $191.1(43.2)$ & \\
\hline \multicolumn{3}{|l|}{$\mathrm{HDL}(\mathrm{mg} / \mathrm{dL})$} \\
\hline Desirable $\geq 40$ & 84 & 61 \\
\hline Low $<40$ & 53 & 39 \\
\hline Missing & 08 & \\
\hline Mean (SD) & $44.2(12.0)$ & \\
\hline \multicolumn{3}{|l|}{ LDL (mg/dL) } \\
\hline Desirable $<100$ & 59 & 43 \\
\hline Near desirable 100-129 & 40 & 29 \\
\hline Bordeline high 130-159 & 27 & 20 \\
\hline High 160-189 & 08 & 6 \\
\hline Very high $\geq 190$ & 03 & 2 \\
\hline Missing & 08 & \\
\hline Mean (SD) & $109.4(36.5)$ & \\
\hline \multicolumn{3}{|l|}{ Triglycerides (mg/dL) } \\
\hline Desirable $<150$ & 70 & 51 \\
\hline Bordeline high 150-199 & 23 & 17 \\
\hline High 200-499 & 37 & 27 \\
\hline Very high $\geq 500$ & 07 & 5 \\
\hline Missing & 08 & \\
\hline Mean (SD) & 194.5 (139.1) & \\
\hline
\end{tabular}

*Lipid profile not done for prediabetic diagnosed through FBS. CVD, cardiovascular disease; FBS, fasting blood sugar; $\mathrm{HbA1c}$, haemoglobin A1c; HDL, high-density lipoprotein; LDL, lowdensity lipoprotein.

be assigned a numeric code. The codes will be given a random number using the STATA command runiform(), with set seed. The participants receiving a random number less than the median value of all the numbers will receive the behavioural intervention. However, no randomisation was done stratified by sex as there were no female workers at these sites.

\section{Behavioural intervention}

The behavioural intervention will consist of a combination of the intensive education session, group counselling, goal setting and monitoring based on the DPP. ${ }^{28}$ The curriculum includes 24 sessions: 16 core sessions weekly during the first 4 months of the programme followed by monthly maintenance sessions. Each class will last 1 hour and will include: (a) $25 \mathrm{~min}$ of scripted lectures on health topics by a health educator; (b) $25 \mathrm{~min}$ of group-based activities, for example, role-playing exercises and group discussions; and (c) $10 \mathrm{~min}$ of physical activity training. Topics to be covered include the importance of maintaining a healthy weight for diabetes prevention and maintaining healthy blood glucose levels, eating a healthy diet, increasing physical activity, overcoming barriers and building social support. At the start of each session, participants will be weighed in a private room to chart their progress. Participants will be given two study goals to achieve during the lifestyle classes, as following: DPP: increase physical activity to at least $150 \mathrm{~min}$ per week of moderate-level activity and lose at least $7 \%$ of their baseline body weight through changes in diet and activity. In the community, there are open spaces for walking, running and playing games such as football and volley. For those who can afford, there are gymnasiums and swimming pools to the locality. The behaviour intervention will be conducted during work hours without any cut in pay. Although there might be some social interactions between the intervention and non-intervention groups, we believe that the core elements of the behaviour intervention (intensive education session, group counselling, goal setting and monitoring, and $20 \mathrm{~min}$ of physical exercise) will not be contaminated as these are tailored programme and cannot be shared with mere interaction. Additionally, it involves 20 min of physical activity which the participants in the non-intervention group cannot inculcate easily.

\section{Canteen intervention}

The canteen intervention will be developed after discussion with canteen operators at the different canteens in the industries and will consist of promoting healthy foods in the canteen by (1) improving the physical facility through enlarging the dining space, increasing the dining space, improving cleanliness and remodelling the kitchen area for the addition of fruit corner; (2) increasing access to healthy foods by adding a salad and fruit corner, whole grains products, low-fat dairy and reducing the sugar, salt, trans-fat and junk food reduction; (3) providing information, education and communication; healthy food options will be displayed in the form of posters and/or paintings mounted in the canteen walls; (4) changing food price: increases in the price of unhealthy foods; decreases in the price of healthy food; (5) training of cafeteria staffs on hygiene, healthy foods options and healthy cooking methods; (6) replacing white rice with brown rice (table 2).

Follow up

Blood samples will be collected and analysed for HbAlc, fasting glucose and lipid profile (HDL, LDL, total cholesterol and triglycerides). We will readminister 
the questionnaires to assess physical activity and usual diet. Additionally, we will measure height, weight, waist circumference and blood pressure. The first follow-up will be conducted after 6 months of the first baseline survey, the second follow-up after 6 months of the start of behavioural intervention and the third follow-up after 6 months after the start of canteen intervention.

\section{Primary and secondary outcomes}

The primary outcome is the absolute change in HbAlc $\%$ and fasting blood glucose. The secondary outcome will be an absolute change in systolic and diastolic blood pressure and in lipids (HDL, LDL, total cholesterol and triglycerides).

\section{Data analysis}

To assess the impact of the behavioural intervention on $\mathrm{HbA1c} \%$ and FBS, the primary analysis will be an intentto-treat comparison of the difference in the changes in HbAlc $\%$ and FBS between the behavioural intervention group and control group, using a two-sample t-test. To assess the effectiveness of the canteen intervention on changes in HbAlc and FBS over the canteen intervention period, a paired t-test will be used among those not randomised to the behavioural intervention in the previous period. Further analyses will adjust for confounding by and assess effect modification by these variables. All the analysis will be conducted using STATA version 13 . In secondary analyses, the same approach will be repeated for lipids, blood pressure, physical activity and diet. Causal mediation analysis will be conducted to quantify the extent to which any changes in health outcomes observed were mediated by changes in physical activity, diet and weight loss.

\section{Ethics and dissemination}

Ethical clearance has been obtained from the Institutional Review Board at the Yale School of Public Health, New Haven, USA and the Ethical Review Committee of the Nepal Health Research Council. Written informed consent will be obtained from the participants before data collection. Data safety and monitoring board will evaluate the safety, study conduct, scientific validity and integrity of the trial. The results of this study will be disseminated by presenting at various national and international academic forums and publications in peerreviewed scientific journals.

\section{Characteristics of the study population}

The mean age \pm SD of the participants were $40.4 \pm 9.7$ years. All were male individuals. The most common ethnicity was Terai Janjati $(53.7 \%)$. Only $13.6 \%$ of the participants had a high school education. Current smokers comprised $12.3 \%$ of the study participants, whereas $66 \%$ consumed $>3$ drinks/week. $42 \%$ of the participants had high MET minutes/week and $5.6 \%$ were obese. Hypertension was seen in $29.6 \%$ of the participants. High cholesterol, very high LDL and very high triglycerides were found in $14.6 \%, 2.2 \%$ and $5.1 \%$ of the participants, respectively.
Low HDL was found in $38.7 \%$ of the participants. The overall assessment of the baseline characteristics of participants showed increased risk factors for diabetes (tables 3-5).

Twitter Sanjib Kumar Sharma @sanjibks1969

Contributors PP, ArS, SKS, BMK and DS contributed substantially to the conception and design of this project. PP, SSB and DT contributed to refining the data collection tools. RKC contributed to the design of the laboratory procedures. AbS, PP and ArS contributed to the formative study. DS, ArS contributed to designing the statistical framework. RMK, AnS and SS refined the manuscript in the initial stage. All authors contributed to final refining and approval of the manuscript.

Funding This study was funded by NIH Director's Pioneer Award (award no: 5DP1ES02545903) and the Bernard Lown Scholar in Cardiovascular Health Program (award no: BLSCHP-1603).

Competing interests None declared.

Patient consent for publication Obtained.

Provenance and peer review Not commissioned; externally peer reviewed.

Data availability statement Data are available upon reasonable request. Data will be available on reasonable request.

Open access This is an open access article distributed in accordance with the Creative Commons Attribution Non Commercial (CC BY-NC 4.0) license, which permits others to distribute, remix, adapt, build upon this work non-commercially, and license their derivative works on different terms, provided the original work is properly cited, appropriate credit is given, any changes made indicated, and the use is non-commercial. See: http://creativecommons.org/licenses/by-nc/4.0/.

ORCID iD

Prajjwal Pyakurel http://orcid.org/0000-0001-5860-9482

\section{REFERENCES}

1 World Health Organization. Global status report on noncommunicable diseases, 2014. Available: https://apps.who. int/iris/bitstream/handle/10665/148114/9789241564854_eng.pdf; jsessionid=05EF28AF84611DB4DC473E4AC6497DFF?sequence=1 [Accessed 10 May 2020].

2 World Health Organization. Global report on diabetes, 2020. Available: https://apps.who.int/iris/bitstream/handle/10665/204871/ 9789241565257_eng.pdf?sequence=1 [Accessed 10 May 2020].

3 International Diabetes Federation. IDF diabetes atlas. 9th edn, 2019. https://www.diabetesatlas.org/upload/resources/material/20200302_ 133351_IDFATLAS9e-final-web.pdf

4 Gyawali B, Sharma R, Neupane D, et al. Prevalence of type 2 diabetes in Nepal: a systematic review and meta-analysis from 2000 to 2014. Glob Health Action 2015;8:29088-13.

5 Nepal Health Research Council. Nepal-non communicable disease risk factors steps survey 2019 fact sheet. Available: http://nhrc.gov. $\mathrm{np} / \mathrm{wp}$-content/uploads/2019/11/National-Factsheet-English-1.pdf [Accessed 10 May 2020].

6 Pyakurel P, Karki P, Lamsal M, et al. Cardiovascular risk factors among industrial workers: a cross-sectional study from eastern Nepal. J Occup Med Toxicol 2016;11:25.

7 Tuomilehto J, Schwarz P, Lindström J. Long-term benefits from lifestyle interventions for type 2 diabetes prevention: time to expand the efforts. Diabetes Care 2011;34:S210-4.

8 Ali MK, Echouffo-Tcheugui J, Williamson DF. How effective were lifestyle interventions in real-world settings that were modeled on the diabetes prevention program? Health Aff 2012;31:67-75.

9 Coughlin SS, Hatzigeorgiou C, Anglin J, et al. Healthy lifestyle intervention for adult clinic patients with type 2 diabetes mellitus. Diabetes Manag 2017;7:197-204.

10 Chen L, Pei J-H, Kuang J, et al. Effect of lifestyle intervention in patients with type 2 diabetes: a meta-analysis. Metabolism 2015;64:338-47.

11 Shrestha A, Karmacharya BM, Khudyakov P, et al. Dietary interventions to prevent and manage diabetes in worksite settings: a meta-analysis. J Occup Health 2018;60:31-45.

12 Shain M, Kramer DM. Health promotion in the workplace: framing the concept; reviewing the evidence. Occup Environ Med 2004;61:643-8.

13 O'Donnell MP. Health promotion in the workplace. Delmar Thomson Learning, 2001. 
14 Baker KM. NIH public access, 2010: 125-38.

15 Bevis CC, Nogle JM, Forges B, et al. Diabetes wellness care: a successful employer-endorsed program for employees. J Occup Environ Med 2014;56:1052-61.

16 Shrestha A, Pyakurel P, Shrestha A, et al. Facilitators and barriers to healthy eating in a worksite cafeteria: a qualitative study from Nepal. Heart Asia 2017;9:e010956.

17 Open Data Kit, 2019. Available: https://opendatakit.org/ [Accessed 10 May 2020].

18 World Health Organization. Global physical activity questionnaire (GPAQ) analysis guide. Available: http://www.who.int/chp/steps/ resources/GPAQ_Analysis_Guide.pdf [Accessed 10 May 2020].

19 Dietary Assessment Primer. 24-Hour dietary recall (24HR) at a glance. National Institutes of health, National cancer Institute. Available: https://dietassessmentprimer.cancer.gov/ [Accessed 9 May 2020].

20 Weighing Review. Crown digital scales. Available: https://www. weighingreview.com/company/crown-digital-scales [Accessed 9 May 2020].

21 Healthline. How to measure your height accurately at home, 2020 Available: https://www.healthline.com/health/how-to-measureheight\#how-to-measure-with-help [Accessed 9 May 2020].

22 Prabhakaran D, Shah P, Chaturvedi V, et al. Cardiovascular risk factor prevalence among men in a large industry of northern India. Natl Med J India 2005;18:59-65.
23 Genc S, Omer B, Aycan-Ustyol E, et al. Evaluation of turbidimetric inhibition immunoassay (TINIA) and HPLC methods for glycated haemoglobin determination. J Clin Lab Anal 2012;26:481-5.

24 Hamid SBS, Omar IC. Determination of total cholesterol in serum by cholesterol oxidase and cholesterol esterase co-immobilized on to cellulose acetate membrane. Pak J Biol Sci 2003;6:1340-4.

25 Coral Clinical Systems. Triglycerides kit (GPO/PAP method) for the determination of triglycerides in serum or plasma (for invitro diagnostic use only). Available: http://www.tulipgroup. com/Coral_New2/html/pack_inserts/Triglycerides\%20Kit.pdf [Accessed 10 May 2020].

26 Atlas Medical. LDL cholesterol direct enzymatic colorimetric method (for in-vitro DiagnosticStore at $2-8^{\circ} \mathrm{C}$ ). Available: http://atlas-medical. com/upload/productFiles/208034/LDL\%20Choleterol\%20Package\% 20Insert.pdf [Accessed 10 May 2020].

27 Coral Clinical Systems. HDL cholesterol kit (PEG/CHOD-PAP method) for the determination of HDL cholesterol in serum or plasma (for invitro diagnostic use only). Available: http://www.tulipgroup. com/Coral_New2/html/pack_inserts/HDL\%20Cholesterol\%20Kit.pdf [Accessed 10 May 2020].

28 Diabetes Prevention Program (DPP) Research Group. The diabetes prevention program (DPP): description of lifestyle intervention. Diabetes Care 2002;25:2165-71. 